excretion than those without stones. This suggests again that idiopathic renal hypercalciuria could have a pathogenic role in patients with recurrent stone formation. ${ }^{11}$

Contributors: See bmj.com

Funding: None.

Competing interests: None declared.

1 Klugman VA, Favus MJ, Pak CYC. Nephrolithiasis in primary hyperparathyroidism. In: Bilezikian JP, Marcus R, Levine MA, eds. The parathyroids: basic and clinical concepts. New York: Raven, 1994:505-17.

2 Silverberg SJ, Shane E, Jacobs TP, Siris ES, Gartenberg F, Seldin D, et al. Nefrolithiasis and bone involvement in primary hyperparathyroidism. Am J Med 1990;89:327-34.

3 Halabe A, Sutton AL. Primary hyperparathyroidism as a cause of calcium nefolithiasis. In: Coe FL, Murray JF, eds. Disorders of bone and mineral metabolism. New York: Raven, 1992:671-84

4 Mollerup CL, Lindewald H. The natural history of renal stone disease after successful parathyroidectomy. World J Surg 1999;23:173-6.
5 Posen S, Clifton-Bligh P, Reeve TS, Wagstaffe C, Wilkinson M. Is parathyroidectomy of benefit in primary hyperparathyroidism? QJ Med 1985 241-51.

6 Vestergaard P, Mollerup CL, Frokjaer V, Christiansen P, Blichert-Toft M, Mosekilde L. Cohort study of risk of fracture before and after surgery for primary hyperparathyroidism. BMJ 2000;321:598-602.

7 Andersen TF, Madsen M, Jorgensen J, Mellemkjaer L, Olsen JH: The Danish national hospital register. Dan Med Bull 1999;46:263-8.

8 Williams JG, Wheeler MH, Aston JP, Brown RC, Woodhead JS. The relationship between adenoma weight and intact (1-84) parathyroid hormone level in primary hyperparathyroidism. Am J Surg 1992;163:301-4.

9 Hedback G, Oden A, Tisell LE. Parathyroid adenoma weight and the risk of death after treatment for primary hyperparathyroidism. Surgery $1995 ; 117: 134-9$

10 Söreide JA, Heerden JA, Grant CS, Lo CY, Ilstrup DM. Characteristics of patients surgically treated for primary hyperparathyroidism with and without renal stones. Surgery 1996;120:1033-7.

11 Froekjaer V, Mollerup CL. Primary hyperparathyroidism: renal calcium excretion in patients with and without renal stones before and after parathyroidectomy. World J Surg 2002;26:532-35.

(Accepted 21 May 2002)

\title{
Insecticide impregnated curtains to control domestic transmission of cutaneous leishmaniasis in Venezuela: cluster randomised trial
}

\author{
Axel Kroeger, Elci Villegas Avila, Linda Morison
}

School of Tropical Medicine, Liverpool L3 5QA

Axel Kroeger

professor of

international

community health

Research Centre

"José W Torrealba,"

Núcleo

Universitario

"Rafael Rangel"

Universidad de los

Andes, Trujillo,

Venezuela

Elci Villegas Avila

lecturer

London School of

Hygiene and

Tropical Medicine,

London

WC1E 7 HT

Linda Morison

lecturer in medical

statistics

Correspondence to:

A Kroeger

A.Kroeger@

liverpool.ac.uk

BMJ 2002;325:810-3

\section{Abstract}

Objective To measure the impact on transmission of leishmaniasis of curtains impregnated with insecticide. Design Cluster randomised controlled trial: household interview survey, observational study of people's behaviour, entomological study with light trap captures of sandflies inside houses.

Setting 14 urban sectors in Trujillo, Venezuela. Participants 2913 inhabitants of 569 houses. Intervention Sectors were paired according to their 12 month cumulative incidence of cutaneous leishmaniasis, one sector in each pair was randomly allocated to receive polyester curtains impregnated with lambdacyhalothrin (intervention group) while the other sector received curtains without insecticide or no curtains (control groups). After 12 months a follow up household survey was conducted.

Main outcome measures Reduction in abundance of sandflies indoors and 12 month incidence of clinical cases of cutaneous leishmaniasis.

Results Transmission of cutaneous leishmaniasis occurred mainly in the domestic setting, with the incidence over 12 months of $4 \%$. The mean number of sandflies per trap per night was 16. After follow up the 12 month incidence of cutaneous leishmaniasis was $0 \%$ in the intervention group and $8 \%$ in the six pairs in the control group that received unimpregnated curtains (mean difference 8, 95\% confidence interval 4.22 to $11.78 ; \mathrm{P}=0.001$ ). There were significantly fewer sandflies in the intervention group (2 $v 15$, mean difference 13 sandflies per trap; 9 to $17 ; \mathrm{P}<0.001$ ).

Conclusion Curtains impregnated with insecticide provide a high degree of protection against indoor transmission of cutaneous leishmaniasis.

\section{Introduction}

American cutaneous leishmaniasis is transmitted by sandflies in rain forest areas mainly among mammals and occasionally humans. However, deforestation has brought vectors and some animal hosts closer to humans, and domestic animals have emerged as alternative reservoirs resulting in an increase in cases of cutaneous leishmaniasis in urban areas. ${ }^{1}$ This trend has been described for several countries. ${ }^{2-8}$

The domestication of transmission has also increased the opportunities for control. Indoor house spraying in Peru, ${ }^{9}$ space spraying in Venezuela, ${ }^{10}$ and curtains impregnated with pyrethroid insecticide in Burkina Faso, ${ }^{11}$ Sudan, ${ }^{12}{ }^{13}$ and Colombia $^{14}$ have considerably reduced sandfly populations.

We carried out a study in an urban area of Venezuela with intense transmission of cutaneous leishmaniasis. We assessed any reduction in abundance of sandflies indoors and of clinical cases in areas with houses protected by curtains impregnated with pyrethroid insecticide compared with areas with houses using nonimpregnated curtains or with no curtains at all. Curtains are preferred to bed nets in urban areas. We received approval for the study from the ethics committee at the Universidad de los Andes, Venezuela.

\section{Methods}

Study area

Trujillo, Venezuela, is 800 metres above sea level, has 33399 inhabitants, and is divided into 22 sectors. It has an annual average temperature of $23.3^{\circ} \mathrm{C}$ and two annual rainfall periods (July and November) of $750 \mathrm{~mm}$ each. The city has many green areas where opossum and other woodland reservoir hosts of Leishmania live. 
The research centre of the university is the main provider of clinical services for cutaneous leishmaniasis. It has identified the vectors ${ }^{15}$ and Leishmania species $^{16}{ }^{17}$ and has mapped sectors of high and low risk. ${ }^{16}$ We carried out this study in high risk areas only, where the estimated annual incidence of cutaneous leishmaniasis was above $0.5 \%$ according to the epidemiological data collected by the centre during the past three years.

\section{Cluster randomised controlled trial (July 2000 to July 2001)}

Baseline household survey (July 2000)-We included 14 sectors of the city, with 569 houses and 2913 inhabitants. The original sample was 578 and the nonresponse rate was only $1.6 \%$. Researchers used a questionnaire at the end of the first annual rainy season to gather data on the demographic (age and sex) and socioeconomic characteristics (formal education, occupation, housing conditions) of the population as well as on people's individual experience with cutaneous leishmaniasis. Additionally, the interviewers examined any scars of lesions. They paid particular attention to "new" cases that had occurred during the 12 months before the interview. Subsequently interviewers checked for any new cases that had been reported in the leishmaniasis clinic in the past 12 months. The consistency of interview answers and clinic records was excellent. Only 25 additional cases, which had been reported in the interviews, could not be identified as these patients had gone to the public hospital. In an observational study researchers visited 50 sample households in the early evening to observe where men, women, and children tended to be at the time when the sandflies were expected to enter the houses.

Entomological baseline study (January to June 2000)-As the lutzomyia sandflies are phototactic ${ }^{515}$ from $6 \mathrm{pm}$ to 7 am we placed light traps in the main room of 565 houses (one trap per house per night) for 150 nights. The sandfly species were determined by professional entomologists.

Randomisation and provision of curtains-We followed the methods of evaluating health interventions at area level ${ }^{18}$ and paired the 14 sectors according to the incidence of cutaneous leishmaniasis in the 12 months before the baseline household survey. For each of the seven pairs we randomly allocated one sector (using computer created random numbers) to the intervention group and the other to the control group, the population being "blind" towards the group allocation. In the intervention group the windows of all 241 houses (with a total of 1336 inhabitants) were covered with loosely hanging polyester curtains impregnated with the pyrethroid insecticide lambdacyhalothrin (ICON 2.5CS, Syngenta, Basle) with a target concentration of $12.5 \mathrm{mg} / \mathrm{m}^{2}$. The mesh size of the curtains was $0.05 \mathrm{~mm}$. After six months all curtains in intervention households were impregnated again. In the 222 houses in six of the control sectors the windows were covered with non-impregnated curtains and in one randomly selected control sector (in pair 7, see table 1) with 106 houses no curtains were provided so we could compare abundance of sandflies in houses with non-impregnated curtains and no curtains at all.

Entomological follow up study (August to October 2000)-We placed light traps in the same houses and in the same way as in the baseline study. There were 239 houses with impregnated curtains (intervention group) and 220 with non-impregnated curtains and 106 houses without curtains (control groups).

Follow up household survey (August 2001)-Twelve months after the baseline survey (again at the end of the rainy season) we used the same questionnaire in the same houses using the same procedure of data collection and quality control. The study populations in the baseline and follow up studies were almost the same: only 15 additional people in the intervention group and 10 in the control group were included in the follow up study.

Data analysis-We entered the survey data on to a computer using EpiInfo v6.4 (CDC, Atlanta, GA, USA) and used EpiInfo, SPSS, and Stata v6 (Statacorp, TX, USA) for analysis. Before the main analysis we used Fisher's exact tests to compare cumulative incidence between intervention and control sectors for each pair. We used cumulative incidence rates of cutaneous leishmaniasis and the average number of flies per trap (house) for each sector as the units of analysis. We compared data at baseline and then at follow up between the intervention and control groups using a paired $t$ test, weighting the data according to the sector size. We also used Wilcoxon's matched pairs test because the small number of pairs made it difficult to assess whether the underlying distribution of the differences was normal (necessary for the validity of the $t$ test), and the Wilcoxon test does not require this assumption. Differences rather than ratios are presented as the estimates of effect because zeroes for the main outcome, cutaneous leishmaniasis, precluded the use of ratios. As one of the control sectors (pair 7) did not receive any curtains, whereas the other control sectors received curtains without insecticide, we carried out separate analyses including and excluding pair 7 .

\section{Results}

\section{Characteristics of population}

The demographic and socioeconomic indicators pointed to moderate levels of poverty: $31 \%$ of the population were children ( $<15$ years old) and only $9 \%$ were 60 years and older; crowding was high (five people per household) but almost all houses had television. Of those people aged over 14 years, 23\% had no school education. Within the same age group $21 \%$ were engaged in domestic activities, $21 \%$ were students, $13 \%$ were manual workers, self employed artisans, or secretaries, $7 \%$ were unemployed, $7 \%$ had an academic profession, and only $2 \%$ were farmers.

Table 1 Mean number of sandflies per trap captured in seven paired urban sectors in baseline and follow up study. Figures in parentheses are number of sandflies/number of traps

\begin{tabular}{lccccc} 
& \multicolumn{2}{c}{ Baseline study } & & \multicolumn{2}{c}{ Follow up study } \\
\cline { 2 - 3 } \cline { 5 - 6 } Pair & Intervention group & Control group & & Intervention group & Control group \\
\hline 1 & $34(738 / 22)$ & $28(937 / 33)$ & & $6(131 / 22)$ & $29(948 / 33)$ \\
\hline 2 & $15(1310 / 87)$ & $19(993 / 52)$ & & $2(141 / 87)$ & $19(1008 / 52)$ \\
\hline 3 & $8(202 / 24)$ & $4(132 / 30)$ & & $<1(13 / 24)$ & $5(146 / 30)$ \\
\hline 4 & $18(396 / 22)$ & $18(348 / 19)$ & & $3(59 / 22)$ & $19(353 / 19)$ \\
\hline 5 & $9(285 / 33)$ & $8(328 / 40)$ & & $2(58 / 33)$ & $9(348 / 40)$ \\
\hline 6 & $7(274 / 40)$ & $12(549 / 46)$ & & $1(38 / 40)$ & $12(549 / 46)$ \\
\hline $7^{\star}$ & $37(406 / 11)$ & $20(2064 / 106)$ & & $5(59 / 11)$ & $20(2116 / 106)$ \\
\hline
\end{tabular}

${ }^{*}$ In pair 7 houses in control group did not receive any curtains. 
Table 2 Incidence of cutaneous leishmaniasis over 12 months in seven paired urban sectors in baseline and follow up study. Figures are numbers (percentage) of cases

\begin{tabular}{|c|c|c|c|c|c|c|}
\hline \multirow[b]{2}{*}{ Pair } & \multicolumn{3}{|c|}{ Baseline study } & \multicolumn{3}{|c|}{ Follow up study } \\
\hline & Intervention group & Control group & $P_{\text {value }}{ }^{*}$ & Intervention group & Control group & P value $^{*}$ \\
\hline 1 & $5 / 120(4)$ & 17/199(9) & 0.2 & $0 / 117$ & $25 / 200(13)$ & 0.004 \\
\hline 2 & $23 / 509(5)$ & $11 / 307(4)$ & 0.6 & $0 / 507$ & $35 / 271(13)$ & $<0.001$ \\
\hline 3 & $3 / 132(2)$ & $6 / 155(4)$ & 0.5 & $0 / 132$ & $3 / 159(2)$ & 0.2 \\
\hline 4 & $6 / 109(6)$ & $5 / 81(6)$ & 1.0 & $0 / 125$ & $12 / 97(12)$ & $<0.001$ \\
\hline 5 & $14 / 246(6)$ & $8 / 161(5)$ & 0.9 & $0 / 246$ & $8 / 168(5)$ & $<0.001$ \\
\hline 6 & $1 / 167(1)$ & $1 / 190(1)$ & 1.0 & $0 / 167$ & $2 / 208$ (1) & 0.5 \\
\hline $7 \dagger$ & $3 / 53(6)$ & $23 / 484(5)$ & 0.7 & $0 / 57$ & $57 / 484(12)$ & 0.01 \\
\hline
\end{tabular}

*Fisher's exact test.

†In pair 7 houses in control group did not receive any curtains.

\section{Baseline epidemiology}

The cumulative rate of non-mucosal cutaneous leishmaniasis (that is, the proportion of people who reported having had cutaneous leishmaniasis once in their lives) was $14 \%(408 / 2913)$. The most common sites of lesions were the legs and arms (79\%). In $88 \%$ of the cases the diagnosis was confirmed by a doctor.

All occupational groups, working either at home or in or around the city, showed only small differences in the cumulative rate of cutaneous leishmaniasis (roughly 23\% in all groups) and the difference between males $(13 \%)$ and females $(15 \%)$ was not significant. This points to transmission being mostly within and around the domestic setting, with little protection according to different levels of housing. Only the small group of farmers on the edge of the urban areas seemed to have an additional risk of infection (15/35, $43 \%)$.

Infection rates were low among the children aged $<5$ years $(3 \%)$ and schoolchildren $(8 \%)$, probably because of the shorter exposure time and the particular protective measures taken with young children. Rates were higher in adults (17\%) and in people aged over 60 years $(21 \%)(\mathrm{P}<0.01$ for difference between children and adults).

The incidence rate of cutaneous leishmaniasis in the 12 months preceding the interview was $4 \%$ (126/2913). The highest number of new cases was registered in July and November, at the end or soon after the rainy season.

\section{Entomological survey}

In the baseline study we captured 8962 sandflies in the 565 houses (on average 16 per trap per night); $63 \%$ of these were principal vectors (Lutzomyia youngi and $L$ ovallesi) and $37 \%$ other vectors ( $L$ scorzai, $L$ trinidadensis, $L$ venezuelensis, $L$ walkeri, $L$ otroclavata, $L$ lichyi).

Impact of impregnated curtains-Table 1 shows the mean number of phlebotomine sandflies per trap before and after the placement of impregnated and non-impregnated curtains. There were no significant differences between the control and intervention groups before the placement of the curtains but afterwards significantly fewer sandflies per house were observed in the sectors with impregnated curtains (mean difference per sector 13 sandflies per trap (95\% confidence interval 9 to $17 ; \mathrm{P}<0.001$ ) compared with those with unimpregnated curtains (see table 3).

Exposure to sandflies (observational study)-Family life in the early evening is centred in the living room around the television. Children under 5 years are put to bed between $8 \mathrm{pm}$ and $9 \mathrm{pm}$ and schoolchildren around $9 \mathrm{pm}$. Between $9 \mathrm{pm}$ to $10 \mathrm{pm}$ the main door is closed and the parents retire to bed. The windows are generally left open during the night, exposing people to the sandflies.

Protective efficacy of curtains-Our main outcome was the 12 month cumulative incidence of cutaneous leishmaniasis. Table 2 shows incidence for each pair of sectors at baseline and after the intervention. There were no significant differences in incidence of cutaneous

Table 3 Comparison of incidence of cutaneous leishmaniasis and abundance of sandflies between intervention and control groups at baseline and follow up

\begin{tabular}{|c|c|c|c|c|c|}
\hline & Intervention group & Control group & Mean difference( $95 \% \mathrm{CI})$ & P value* & $P$ value \\
\hline \multicolumn{6}{|c|}{ No (\%) of cases of cutaneous leishmanisasis } \\
\hline \multicolumn{6}{|c|}{ Baseline: } \\
\hline 7 pairs & $55 / 1336(4.1)$ & $71 / 1577(4.5)$ & $0.3(-0.8$ to1.4) & 0.574 & 0.866 \\
\hline 6 pairsł & $52 / 1283(4.1)$ & 47/1093 (4.5) & $0.4(-0.8$ to 1.6$)$ & 0.488 & 0.600 \\
\hline \multicolumn{6}{|l|}{ Follow up: } \\
\hline 7 pairs & $0 / 1351$ & $142 / 1587(9.0)$ & $8.3(5.0$ to 11.7$)$ & $<0.001$ & 0.018 \\
\hline 6 pairsł & $0 / 1294$ & $85 / 1103(7.7)$ & $8.0(4.2$ to 11.8$)$ & 0.001 & 0.028 \\
\hline \multicolumn{6}{|c|}{ No (mean) of sandflies per trap } \\
\hline \multicolumn{6}{|c|}{ Baseline: } \\
\hline 7 pairs & $3611 / 239(15)$ & $5351 / 326(16)$ & $-1(-5$ to 4$)$ & 0.706 & 0.499 \\
\hline 6 pairs $\ddagger$ & $3205 / 228(14)$ & $3287 / 220(15)$ & $1(-2$ to 4$)$ & 0.427 & 0.916 \\
\hline \multicolumn{6}{|l|}{ Follow up: } \\
\hline 7 pairs & $499 / 239(2)$ & $5468 / 326(17)$ & 14 (10 to 17$)$ & $<0.001$ & 0.018 \\
\hline 6 pairsł & $440 / 228(2)$ & $3352 / 220(15)$ & 13 (9 to 17$)$ & $<0.001$ & 0.028 \\
\hline
\end{tabular}

*From paired $t$ test (weighted probability proportional to size of cluster)

†From matched pairs Wilcoxon test.

łExcluding pair 7, in which houses in control group did not receive any curtains. 


\section{What is already known on this topic}

The transmission of cutaneous leishmaniasis is increasingly in urban and domestic settings

House spraying, space spraying, and insecticide treated material reduce the number of vectors

\section{What this paper adds}

Pyrethroid impregnated curtains can considerably reduce the incidence rate of cutaneous leishmaniasis in areas where indoor transmission is predominant

leishmaniasis between the groups before placement of the curtains. After the intervention the incidence in the group that received impregnated curtains was 0 and significantly lower than the group which received unimpregnated curtains (mean difference in 12 month incidence 8 cases per sector; 4 to $12 ; \mathrm{P}=0.001$ ) (table 3 ).

\section{Side effects}

We observed no side effects of the pyrethroid impregnated curtains and none was reported in the interviews in the follow up study.

\section{Discussion}

This randomised trial has shown that curtains impregnated with insecticide are effective in protecting people from bites from sandflies that can transmit cutaneous leishmaniasis. One Columbian village study with bed nets impregnated with deltamethrin $\left(26 \mathrm{mg} / \mathrm{m}^{2} \text { target concentration }\right)^{14}$ and laboratory experimental studies in Colombia ${ }^{14}$ and Venezuela ${ }^{19}{ }^{20}$ have shown that high pyrethroid concentrations and fabrics with fine mesh provide an effective barrier. In our study the mesh was much finer but the barrier effect of the loosely hanging curtains in the open windows was low when they were not treated and high when they were impregnated.

Our results are probably due to two factors. Firstly, almost all the transmission of cutaneous leishmaniasis was within the domestic setting, and, secondly, we achieved a substantial reduction in abundance of the vector in intervention houses, although in the early evening entrance doors were generally kept open. The reason may be a repellent effect against the local Lutzomyia species (such an effect has not been described for permethrin-impregnated curtains against Phlebotomus orientalis in Sudan ${ }^{12}$ and deltamethrin impregnated curtains against $L$ ovallesi and $L$ gomez $i$ in Venezuela ${ }^{1}$ ) and the fact that a large proportion of these flies enter later at night when the doors are closed ( $L$ ovallesi abundance peaks between $10 \mathrm{pm}$ and midnight and then decreases ${ }^{21}$ ).

We conclude that curtains impregnated with lambdacyhalothrin (pyrethroid) provide good protection against transmission of cutaneous leishmaniasis in areas with similar epidemiological and entomological characteristics as those in Trujillo. Further studies on the use of pyrethroids against Lutzomyia species as well on the operational feasibility of sustainable impregnation services in Trujillo are under way.
We thank the staff of the research centre "José W Torrealba" in Trujillo, particularly José Vicente Scorza and Elina Rojas for the support of the research in Trujillo; Alfredo Briceño for assistance during field studies; and Rafael Barazarte for identifying the sandflies. We also thank all inhabitants in our study communities who answered our questions and accepted the intervention.

Contributors: AK and EV substantially contributed to the design, execution, and analysis of the study; the statistical analysis was done by $\mathrm{LM}$. AK is guarantor.

Funding: European Commission (contract Alfa Programme 6-0011-9 and INCO-DEV IC18CT 980339); no inputs into the research itself. The insecticide was donated by Syngenta.

Competing interests: None declared.

1 Campbell-Lendrum D, Dujardin JP, Martinez E, Feliciangeli MD, Perez JE de Silans LVMP, et al. Domestic and peridomestic transmission of American cutaneous leishmaniasis: changing epidemiological patterns present new control opportunities. Mem Inst Oswaldo Cruz 2001;96:159-62.

2 Davies CR, Reithinger R, Campbell-Lendrum D, Borges R, Rodriguez N. The epidemiology and control of leishmaniasis in Andean countries. Cad Saude Publica 2000;16:925-50.

3 Martinez E, Le Pont F, Torrez M, Telleria J, Vargas F, Muñoz M, et al. A new focus of cutaneous leishmaniasis due to Leishmania amazonensis in a sub Andean region of Bolivia. Acta Trop 1998;15:97-106.

4 Torrez M, Lopez M, Le Pont F, Martinez E, Muñoz M, Hervas D, et al. Lutzomvia nuñeztovari anglesi (Diptera: Psychodidae) as a probable vector of Leishmania braziliensis in the Jungas, Bolivia. Acta Trop 1999;71:311-6.

5 Feliciangeli MD. Ecology of sandflies (Diptera: Psychodidae) in a resticted focus of cutaneous leishmaniasis in northern Venezuela. II. Species composition in relation to habitat, catching method and hour of catching. Mem Inst Oswaldo Cruz 1987:82:125-31.

6 Scorza JV.Cambios epidemiológicos de la leishmaniasis tegumentaria en Venezuela. Bol Direccion Malariol Saneamiento Ambiental 1986;25:45-8.

7 Brandao-Filho SP, Campbell-Lendrum D, Brito MEF, Shaw JJ, Davis CR. Epidemiological surveys confirm increasing burden of cutaneous leishmaniasis in north-east Brazil. Trans R Soc Trop Med Hyg 1999;93: $488-94$.

8 Tolezano JE. Epidemiological aspects of American cutaneous leishmaniasis in the State of Sao Paulo, Brazil. Mem Inst Oswaldo Cruz 1994;89: 427-34.

9 Davies CR, Llanos-Cuentas EA, Campos P, Monge J, Leon E, Canales JL. Spraying houses in the Peruvian Andes with lambda-cyhalothrin protects residents against cutaneous leishmaniasis. Trans $R$ Soc Trop Med Hyg 2000;94:631-6.

10 Scorza JV, Rojas E, Rosario CL, Espinoza A, Rosas C, Mendoza AB, et al. Control temporal de la transmisión de leishmaniasis cutanea urbana en Venezuela, mediante nebulizaciones con ICON. Bol Direccion Malario Saneamiento Ambiental 1999:39:83-9.

11 Majori M, Maroli M, Sabatinelli G, Fausto AM. Efficacy of permethrinimpregnated curtains against endophilic phlebotomine sandflies in Burkina Faso. Med Vet Entomol 1989;3:441-4.

12 Elnaiem DA, Elnahas AM, Aboud MA. Protective efficacy of lambdacyhalothrin-impregnated bednets against Phlebotomus orientalis, the vector of visceral leishmaniasis in Sudan.1999. Med Vet Entomol 1999;13:310-4

13 Elnaiem DA, Aboud MA, El Mubarek SG, Hassan HK, Ward RD. Impac of pyrethroid-impregnated curtains on Phlebotomus papatasi sandflies indoor at Hartoun, Sudan.1999a. Med Vet Entomol 1999;13:191-7.

14 Alexander BU, Cadena H, Quesada BL, Solarte Y, Rosa W, Travi VL. Evaluation of delthamethrin-impregnated bed nets and curtains against phlebotomine sandflies in Valle del Cauca, Colombia. Med Vet Entomol 1995;9:279-83.

15 Scorza JV, Rojas E. Actividad intradomiciliar de Lutzomyia youngi (Diptera: Psychodidae) en Venezuela. Bol Direccion Malariol Saneamiento Ambiental 1989;29:64-70.

16 Scorza JV, Rojas E. La leishmaniasis tegumentaria venezolana: problemática conteporánea en el estado Trujillo. Bol Direccion Malariol Saneamiento Ambiental 1990:30:14-6.

17 Guevara P, Ramirez JL, Alonso G, Rojas E, Scorza JV, Añez N, et al. Identification and diagnosis of leishmania based on ribosomal intergenic spacer sequences. Mem Inst Oswaldo Cruz 1993;88:80.

18 Ukoumunne OC, Gulliford MC, Chinn S, Sterne JA, Burney PGJ, Donner A. Evaluation of health interventions at area and organisation level. $B M$ 1999;319:376-86.

19 Feliciangeli MD, Wheeler A, Towson H, Ward R, Maignon R. Sandfly control trial with deltamethrin impregnated curtains in el Ingenio, Miranda state Venezuela. Bol Direccion Malariol Saneamiento Ambiental 1995;35:127-35

20 Perruolo G. Factibilidad de utilización de cortinas impregnadas con delthametrina para el control de flebótomos. Bol Direccion Malariol Saneamiento Ambiental 1995;35:295-304

21 Feliciangeli MD. Hourly activity of Lutzomyia ovallesi and Lu.gomezi (Diptera Psychodidae), vectors of cutaneous leishmaniasis in north central Venezuela. J Med Entomol 1997;34:110-5.

(Accepted 8 August 2002) 